\title{
Somatic Mutations in Human Cancer: Insights from Resequencing the Protein Kinase Gene Family
}

\author{
P.A. Futreal, R. Wooster, and M.R. Stratton \\ Cancer Genome Project, Wellcome Trust Sanger Institute, Hinxton, CB10 1SA, United Kingdom
}

\begin{abstract}
All cancers arise due to the accumulation of mutations in critical target genes that, when altered, give rise to selective advantage in the cell and its progeny that harbor them. Knowledge of these mutations is key in understanding the biology of cancer initiation and progression, as well as the development of more targeted therapeutic strategies. We have undertaken a systematic screen of all annotated protein kinases in the human genome for mutations in a series of cancers including breast, non-small-cell lung, and testicular cancer. Our results show a wide diversity in mutation prevalence within and between tumor types. We have identified a mutator phenotype in human breast previously undescribed. The results presented from sequencing the same 1.3 million base pairs through several tumor types suggest that most of the observed mutations are likely to be passenger events rather than causally implicated in oncogenesis. However, this work does provide evidence for the likely existence of multiple, infrequently mutated kinases.
\end{abstract}

Cancer is a disease of DNA. All cancers arise due to the accumulation of mutations in DNA sequence. These sequence alterations give rise to mutations in critical target genes that ultimately provide a selective growth advantage for the cells harboring them, leading to the clinical manifestations of cancer. The identification of mutated genes in human cancer has been a major focus of cancer research for the past three decades. Identification of these mutations and the cellular pathways that are subverted holds the promise of better diagnostics and more targeted therapies. As well, a more general understanding of mutation prevalence and pattern in cancers will inform on both extrinsic and intrinsic erosive processes that buffet the genome, leading to oncogenesis as well as potential deficits in handling DNA damage.

Mutations in cancer can take the form of chromosomalscale events such as rearrangements and translocations; subchromosomal alterations in the form of deletions and amplifications; and smaller-scale events comprising insertions, deletions, and base-pair substitutions. As well, the state of DNA methylation can be altered in cancers, providing an epigenetic means for gene deregulation.

Perhaps the least well investigated category of DNA alterations in cancer is that of point mutations-small insertions/deletions and substitutions. Genes primarily targeted by this class of mutation may leave few other positional clues (such as translocation, amplification, germ-line susceptibility alleles) to expedite their identification. Evidence from our recent census of cancer genes suggests that point-mutated genes are underrepresented, particularly in the solid tumors which comprise the bulk of the cancer burden in the population (Futreal et al. 2004). We have undertaken a systematic resequencing approach to ascertain those genes with mutations in this class with the hope of identifying important target genes and to begin to investigate the patterns of somatic mutation in a variety of human cancers.

\section{WHY START WITH PROTEIN KINASES?}

We have chosen the family of protein kinases as a first set of genes for resequencing efforts. Genes containing a protein kinase encoding domain are the most frequently mutated in human cancer. Kinases function as key molecular controllers of virtually all cellular processes including cell growth, division and apoptosis - all frequently aberrant in human cancer. As well, kinases have proven to be the most tractable class of proteins for the development of targeted therapeutics in cancer to date. Targeted inhibition of amplified ERBB2/HER2-neu receptor in metastatic breast cancer with trastuzumab (Herceptin) (a humanized monoclonal antibody) is the first example of targeted exploitation of a kinase target in cancer therapy (Slamon et al. 2001). The clinical efficacy of imatinib (Gleevec), a small-molecule inhibitor of rearranged and mutated $A B L$, $K I T$, and PDGFRA/B kinases, in chronic myelogenous leukemia (CML), gastrointestinal stromal tumors, and idiopathic hypereosinophilic syndrome has established the paradigm for small-molecule-inhibitor-based therapeutics in cancer (Sawyers 2004). Intragenic activating mutations in the EFGR gene have been shown to be important mediators of significant response to small-molecule EGFR inhibitors in stage III-IV adenocarcinoma of the lung (Lynch et al. 2004; Paez et al. 2004; Pao et al. 2004), thus extending the imatinib model into an adult epithelial cancer with undoubtedly more complex genetic alterations. Although the responses in lung cancer patients to two EGFR inhibitors, gefitinib (Iressa) and erlotinib (Tarceva), are not as dramatic or durable as those seen in CML with imatinib, they nevertheless show that targeted molecular therapeutics are active in an epithelial cancer which is otherwise refractory to treatment. This potential therapeutic vulnerability of cancers when treated with agents directed at specific mutated genes has been referred to as "oncogene addiction." In this model, a cancer be- 
comes dependent on (addicted to) a particular oncogenically (mutationally) activated pathway for its survival, thus making that pathway particularly attractive for therapeutic intervention (Weinstein 2002).

More recently, the development of clinical resistance to both imatinib in CML and gefitinib in lung adenocarcinoma has been shown to be due to specific point mutations within the kinase domain binding site for the drug, further illustrating the critical role of the target gene in treatment efficacy (Gorre et al. 2001; Kobayashi et al. 2005). Certainly the success of exploiting mutated kinase targets and, conversely, the emergence of clinical resistance when targeting kinases with small-molecule inhibitors, suggest that further identification of mutated kinases in human cancer will provide an important opportunity for both the development of de novo therapeutics and the beginnings of poly-molecular therapy for cancer.

\section{RESEQUENCING THE PROTEIN KINASES- OVERALL RESULTS}

The protein kinase family comprises 518 genes (Manning et al. 2002). We have resequenced the coding exons plus splice junctions of the entire family $(\sim 1.3$ million base pairs $[\mathrm{Mb}] /$ sample) in a series of 25 breast cancers, 33 non small-cell lung cancers (NSCLC), and 13 testicular germ-cell tumors (TGCT) (Table 1). In total, $92 \mathrm{Mb}$ of sequence were generated from the 71 samples analyzed, providing the most in-depth analysis of somatic mutations in human cancer undertaken to date.

In each case studied there was a matching DNA sample from normal tissue (usually peripheral blood) from the same individual to verify the somatic nature of the observed mutations. Each coding exon including splice junctions was amplified and sequenced bidirectionally from tumor DNA. Any amplicon containing a sequence variant that was not an obvious single-nucleotide polymorphism (SNP) (present in dbSNP http://www.ncbi. nlm.nih.gov/SNP/ or previously observed to be a germline polymorphism in in-house sequencing efforts) was then amplified from matching normal DNA for the particular case. If the variant was not present in the germ-line DNA, indicating the mutation to be of somatic origin, both tumor and normal were reamplified and sequenced to confirm the somatic mutation. For a subset of genes with somatic mutations, a follow-up study in an independent set of cancers of roughly twice the size of the original screen was undertaken to investigate prevalence.

In total, we identified 279 somatic mutations distributed among 78 genes in the 71 sample ( 92 megabases) screens under discussion; 185 missense, 25 nonsense, 6 frameshift, 3 in-frame deletion, 12 consensus splice site, and 48 silent mutations were identified (http://www. sanger.ac.uk/genetics/CGP/Kinases/) (Bignell et al. 2005; Davies et al. 2005; Stephens et al. 2005). Of note, the rate of silent mutations (unlikely to be under selective pressure) reflects the minimum rate of somatic mutation "noise" to be dealt with in any such large-scale resequencing endeavor.

The most frequently mutated gene was TTN, encoding the Titin giant sarcomeric protein, with 15 somatic muta- tions. Monte Carlo simulation analysis of mutation distribution by coding "footprint" size showed that mutations were not found any more often than predicted by chance when size of coding sequence was taken into account, suggesting that numbers of mutations per se was not a reliable indicator of presumptive oncogenic potential. Additional analyses included manual scrutiny for clustering in genes, for occurrence at conserved positions that are known to be mutated in other kinases, and for tumor type clustering.

To assess potential selection for coding (nonsynonymous) mutations, each nucleotide of the 1.3-Mb coding footprint of the protein kinases was mutated in silico to each of the other three bases (correcting for the observed mutational spectrum and sequence context of mutations), the resulting sequence was translated, and the mutations were classified into missense, nonsense, and silent (synonymous) changes. A higher than expected ratio of nonsynonymous:synonymous (nonsyn:syn) changes (which varies from $2: 1$ to $3: 1$ depending on the mutational spectrum) suggests that mutations which change the coding sequence are being selected and, hence, that a proportion of mutations detected may be implicated in cancer causation. For both the breast and lung screens, there was evidence for an excess of nonsynonymous changes, suggesting that proportion of mutations identified are likely contributory to oncogenesis, although any one was only mutated at low frequency. Even so, our data suggest that the majority of somatic mutations identified are passenger events and, as such, are significant confounders in trying to identify rare oncogenic mutations. Overall, the screens have not identified a frequently mutated protein kinase in the tumor types examined. However, given the small sample numbers and likely impact of tumor heterogeneity, additional screens are warranted.

The overall distribution of mutations among the samples examined is shown in Figure 1. Most striking is the diversity of mutation prevalence among and between tumor types examined. In general, NSCLC had the most mutations/sample examined, followed by breast cancer, then TGCT. Cancer cell lines tended to have more mutations than the primary cancers examined, but this trend was not particularly exaggerated in the NSCLC. For breast cancers, the cell lines comprised a select subset of breast cancers. All were TP53 mutant, and all but one were derived from a premenopausal breast cancer. However, there was one cell line that had no mutations. For primary tumors, each screen yielded a subset that had no detectable somatic mutations. This was most striking in TGCT, where 12 out of 13 cases had no detectable mutations. Within NSCLC, no carcinoid $(n=6)$ had a somatic mutation. Likewise, the majority of breast cancer primaries $(12 / 16)$ had no mutations.

TGCT was included in these initial screens due to its unique clinical behavior. It is the only solid tumor curable with chemotherapy in the metastatic setting, despite being markedly aneuploid in nearly all cases (Oosterhuis and Looijenga 2005). We detected only a single somatic point mutation in over $15 \mathrm{Mb}$ of sequence in this tumor type, giving it perhaps the lowest mutation prevalence yet observed. Such evidence is supportive of a model of chemosensitivity where there is demonstrable DNA re- 
Table 1. Samples Screened for Somatic Mutations in the Protein Kinases

\begin{tabular}{|c|c|c|c|c|c|}
\hline Sample & Study & Histology & Age at diagnosis & Sex & Smoking status \\
\hline PD0025a & breast & IDC & 83 & female & ND \\
\hline PD0062a & breast & IDC & 37 & female & ND \\
\hline PD0091a & breast & IDC & 83 & female & ND \\
\hline PD0118a & breast & IDC & 78 & female & ND \\
\hline PD0119a & breast & pleomorphic lobular & 84 & female & ND \\
\hline PD0127a & breast & IDC & 81 & female & ND \\
\hline PD0128a & breast & IDC & 85 & female & ND \\
\hline PD1232a & breast & mucinous & 85 & female & ND \\
\hline PD1233a & breast & IDC & 38 & female & ND \\
\hline PD1234a & breast & IDC & 43 & female & ND \\
\hline PD1235a & breast & IDC & 38 & female & ND \\
\hline PD1236a & breast & IDC & 47 & female & ND \\
\hline PD1237a & breast & IDC & 55 & female & ND \\
\hline PD1238a & breast & IDC & 36 & female & ND \\
\hline PD1239a & breast & IDC & 73 & female & ND \\
\hline PD1241a & breast & IDC & 45 & female & ND \\
\hline HCC38 & breast & IDC & 50 & female & ND \\
\hline HCC 1143 & breast & IDC & 52 & female & ND \\
\hline HCC 1187 & breast & IDC & 41 & female & ND \\
\hline HCC1395 & breast & IDC & 43 & female & ND \\
\hline HCC 1599 & breast & IDC & 44 & female & ND \\
\hline HCC 1937 & breast & IDC & 23 & female & ND \\
\hline HCC 1954 & breast & IDC & 61 & female & ND \\
\hline HCC 2157 & breast & IDC & 48 & female & ND \\
\hline $\mathrm{HCC} 2218$ & breast & IDC & 38 & female & ND \\
\hline PD0248a & NSCLC & $\mathrm{SCC}$ & 57 & male & previous smoker \\
\hline PD0250a & NSCLC & carcinoid & 61 & female & nonsmoker \\
\hline PD0251a & NSCLC & $\mathrm{SCC}$ & 57 & male & current \\
\hline PD0252a & NSCLC & BAC & 83 & male & previous smoker \\
\hline PD0253a & NSCLC & adeno & 60 & male & current \\
\hline PD0263a & NSCLC & $\mathrm{LC}$ & 81 & male & previous smoker \\
\hline PD0269a & NSCLC & $\mathrm{SCC}$ & 52 & male & current \\
\hline PD0276a & NSCLC & $\mathrm{LC}$ & 71 & male & previous smoker \\
\hline PD1240 & NSCLC & $\mathrm{SCC}$ & 69 & male & unknown \\
\hline PD1339a & NSCLC & adeno & 65 & male & previous smoker \\
\hline PD1345a & NSCLC & adeno & 65 & male & current \\
\hline PD1351a & NSCLC & adeno & 67 & male & unknown \\
\hline PD1352a & NSCLC & adeno & 58 & male & current \\
\hline PD1353a & NSCLC & adeno & 65 & male & previous smoker \\
\hline PD1354a & NSCLC & carcinoid & 71 & female & nonsmoker \\
\hline PD1355a & NSCLC & carcinoid & 40 & male & previous smoker \\
\hline PD1356a & NSCLC & carcinoid & 60 & female & previous smoker \\
\hline PD1359a & NSCLC & carcinoid & 52 & female & previous smoker \\
\hline PD1360a & NSCLC & carcinoid & 34 & female & nonsmoker \\
\hline PD1362a & NSCLC & $\mathrm{LC}$ & 64 & male & previous smoker \\
\hline PD1364a & NSCLC & $\mathrm{LC}$ & 57 & female & previous smoker \\
\hline PD1365a & NSCLC & $\mathrm{LC}$ & 61 & female & nonsmoker \\
\hline PD1367a & NSCLC & $\mathrm{LC}$ & 53 & male & previous smoker \\
\hline PD1370a & NSCLC & $\mathrm{SCC}$ & 68 & male & previous smoker \\
\hline PD1373a & NSCLC & $\mathrm{SCC}$ & 60 & female & previous smoker \\
\hline PD1379a & NSCLC & SCC & 76 & male & current \\
\hline NCI-H1395 & NSCLC & adeno & 55 & female & current \\
\hline NCI-H1437 & NSCLC & adeno & 60 & male & current \\
\hline NCI-H1770 & NSCLC & adeno & 57 & male & nonsmoker \\
\hline NCI-H2009 & NSCLC & adeno & 68 & female & current \\
\hline NCI-H2087 & NSCLC & adeno & 69 & male & current \\
\hline NCI-H2122 & NSCLC & adeno & 46 & female & current \\
\hline NCI-H2126 & NSCLC & adeno & 65 & male & unknown \\
\hline PD1381a & testis & SGCT & 29 & male & ND \\
\hline PD1382a & testis & SGCT & 31 & male & ND \\
\hline PD1383a & testis & SGCT & 50 & male & ND \\
\hline PD1384a & testis & SGCT & 72 & male & ND \\
\hline PD1385a & testis & SGCT & 28 & male & ND \\
\hline PD1386a & testis & SGCT & 31 & male & ND \\
\hline PD1388a & testis & SGCT & 22 & male & ND \\
\hline PD1389a & testis & NSGCT (EC TE YST) & 26 & male & ND \\
\hline PD1391a & testis & NSGCT (EC TE YST) & 37 & male & ND \\
\hline PD1392a & testis & NSGCT (TE YST) & 30 & male & ND \\
\hline PD1394a & testis & NSGCT (EC YST TE) & 31 & male & ND \\
\hline PD1395a & testis & NSGCT (YST) & 32 & male & ND \\
\hline PD1396a & testis & NSGCT (EC YST TE) & 26 & male & ND \\
\hline
\end{tabular}

(NSCLC) Non-small-cell lung cancer; (IDC) infiltrating ductal carcinoma; (SCC) squamous cell carcinoma; (BAC) bronchoalveolar carcinoma; (adeno) adenocarcinoma; (LC) large cell carcinoma; (SGCT) seminomatous germ-cell tumor; (NSGCT) non-seminomatous germ-cell tumor; (EC) embryonal carcinoma; (TE) teratoma; (YST) yolk sac tumor; (ND) no data. PD numbered samples are primary tumors. 


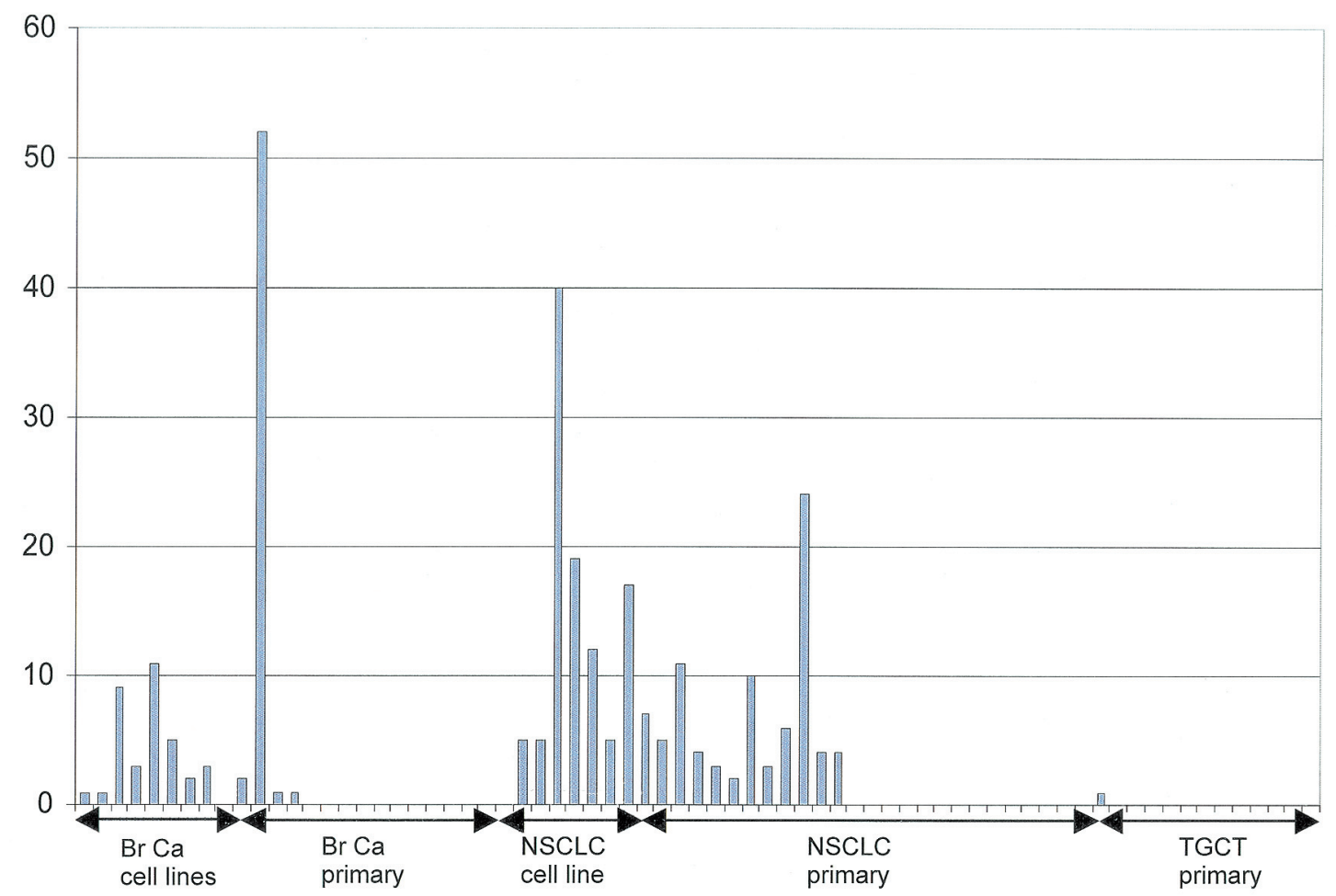

Figure 1. Somatic mutations in protein kinases by tumor type. Numbers of somatic mutations detected in resequencing the protein kinase gene are shown for each sample type. Y axis indicates the numbers of somatic mutation in each sample. Arrow brackets are provided to delineate specific sample subsets.

pair deficiency coupled with highly active apoptotic responses such that cells which accrue DNA damage are efficiently killed. Resequencing efforts will begin to provide more data to explore the relationship of somatic mutation prevalence, DNA repair competence, and response to therapy.

These screens allow more precise estimation of the absolute frequency of somatic mutations in cancer genomes as a whole. On the assumption that the $1.3-\mathrm{Mb}$ protein $\mathrm{ki}-$ nase coding sequence is, to some extent, a representative sample of the genome, we can estimate the numbers of somatic mutations in each cancer genome and the numbers of consequent "bystander" amino acid changes. Some individual cancers have as many as 100,000 somatic mutations in their genomes, encoding approximately 1,000 amino acid changes (in 1:30 genes). In contrast, it appears that most breast and testis cancers have fewer than 2,000 somatic point mutations and fewer than 20 bystander amino acid changes.

\section{RESEQUENCING THE PROTEIN KINASES- A NEW BREAST CANCER MUTATOR PHENOTYPE}

Our analyses have demonstrated substantial diversity of mutation number and pattern in individual breast cancers. Particularly striking was primary tumor PD0119a (a pleomorphic lobular carcinoma occurring in an 84-yearold woman), which had 52 somatic mutations, more than all other breast cancer samples combined. The cancer was $\mathrm{ER}^{+}, \mathrm{ERRB}^{-}$, TP53 mutation-negative, and negative for
E-cadherin staining, consistent with a luminal-ductal origin. The mutation spectrum in the cancer is characterized by a high frequency of $\mathrm{C}: \mathrm{G}>\mathrm{G}: \mathrm{C}$ transversions occurring at $\mathrm{TpC}(\mathrm{GpA})$ dinucleotides (Fig. 2). Inactivating mutations in BRCA1 or BRCA2 are not associated with this mutational spectrum, and it is not obviously similar to any reported eukaryotic repair defect. The data suggest the characterization of a novel mutator phenotype in human breast cancer, although formally, the results could be due to a massive exposure. Of note, at least one breast cancer cell line appears to have a similar phenotype, derived from a ductal carcinoma in a 38-year-old (Fig. 2). This observation supports the existence of mutator phenotype in breast cancer. It is important to note that the only way currently to identify and characterize such phenotypes is through in-depth sequencing.

\section{RESEQUENCING THE PROTEIN KINASES- MUTATED GENES}

Several genes with somatic mutations identified in the screens are worth highlighting. We detected a single inframe insertion in the kinase domain of $E R B B 2$ of a NSCLC primary sample, prompting a further screen of this gene in a larger series of cancers. Data from a larger series of primary NSCLC showed that ERBB2 mutations are present in about $10 \%$ of lung adenocarcinoma (Stephens et al. 2004). This was the first report of intragenic mutation in this well-studied cancer gene. Mutations were found in the kinase domain affecting the $\alpha \mathrm{C}$ helix region, similar to the deletion mutations found in 
50

Primary Breast Cancer PD0119

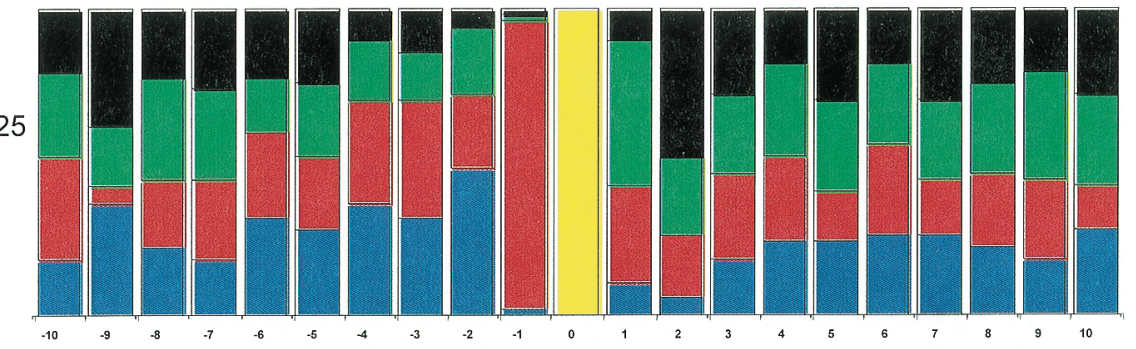

10

Breast Cancer cell line HCC2218

5

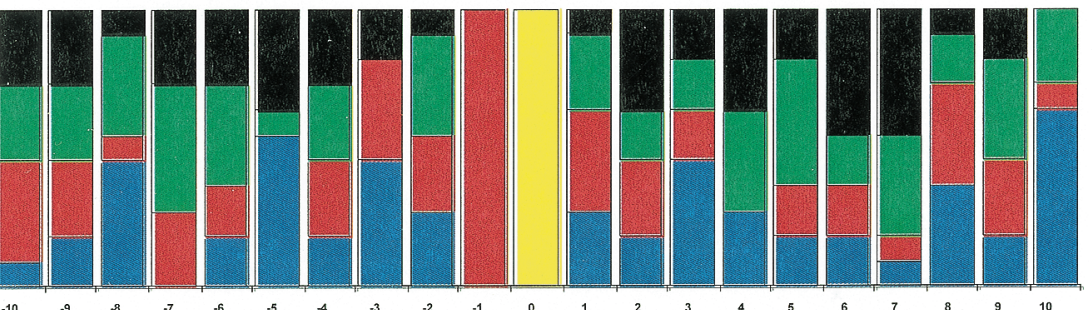

TP53 Breast Cancer

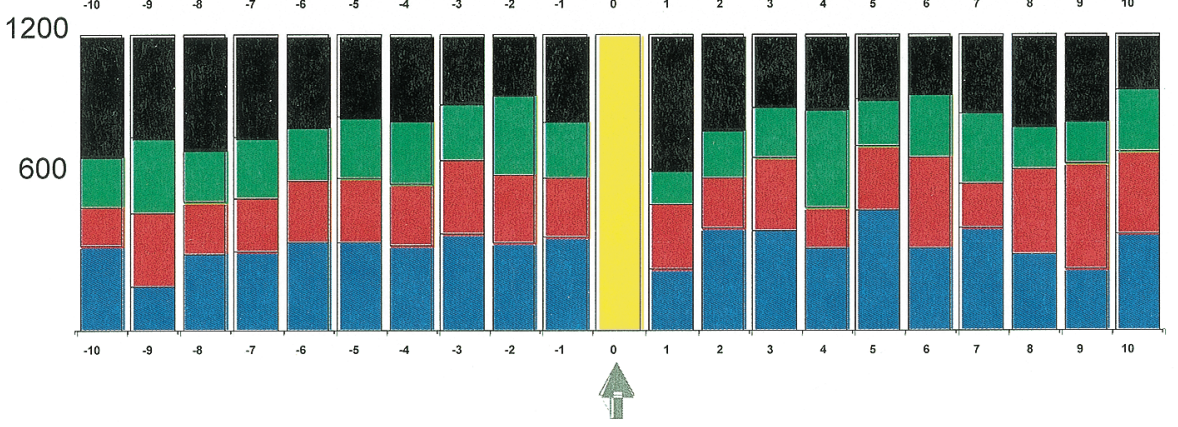

Figure 2. Sequence context specificity for the mutator phenotype breast cancer. Arrow and yellow bar indicate the position of $\mathrm{C}: \mathrm{G}>\mathrm{G}: \mathrm{C}$ transversion mutations identified. Numbering is relative to the position of the mutation. All mutations were regularized to the "C" strand for this analysis. Note the almost complete predominance of a T residue before the mutated C. The sequence of TP53 $\mathrm{C}: \mathrm{G}>\mathrm{G}: \mathrm{C}$ transversion mutations in breast cancer is shown for comparison. Red $=\mathrm{T}$, green $=\mathrm{A}$, blue $=\mathrm{C}$, black $=\mathrm{G}$. TP53 data from http://www-p53.iarc.fr/

EFGR (Lynch et al. 2004; Paez et al. 2004; Pao et al. 2004). Mutant $E R B B 2$ was neither overexpressed nor amplified in the cases examined. We found no obvious correlation with smoking history or sex, unlike subsequent studies (Shigematsu et al. 2005). Additional rare ERBB2 mutations were found in cases of gastric cancer, ovarian cancer, and glioblastoma. Subsequent studies have reported low-frequency mutations (Sasaki et al. 2005), suggesting that $E R B B 2$ mutations, like those found in $E G F R$, may be restricted to specific subsets of NSCLC. Further work is needed to more clearly delineate the characteristics of this cohort to investigate the potential for the treatment of this subset of patients with anti-ERBB2 therapies.

Activating germ-line mutations of the fibroblast growth factor receptors, FGFR1, FGFR2, and FGFR3, have been reported in skeletal dysplasias (Wilkie et al. 2002). Somatic mutations of FGFR3 found in papillary transitional-cell bladder cancer affect identical positions to germ-line mutations predisposing to thanatophoric dwarfism (Cappellen et al. 1999). Analogous to these data, we identified a somatic mutation in FGFR1 (pP252T) in a bronchoalveolar NSCLC affecting a key codon known to have mutated in the skeletal dysplasia Pfeiffer syndrome (Human Gene Mutation Database, http://archive.uwcm.ac.uk/uwcm/mg/hgmd0.html). Likewise, a somatic mutation was identified in FGFR2 (pW290C) in a squamous cell lung carcinoma at an identical position reported for germ-line mutations in the skeletal dysplasias, craniosynostosis, Crouzon, and Pfeiffer syndromes. FGFR2 point mutations have been previously described only in gastric cancer-again at residues analogous to germ-line mutations. These results strongly suggest that mutations in FGFR1 and FGFR2 are likely to play a role, albeit uncommonly, in lung carcinogenesis. Further work is needed to determine the rates and subtype distributions of FGFR mutations and the possible role of FGFR kinase inhibitors in lung cancer therapy.

Somatic mutations within the catalytic loop (pR678Q, $\mathrm{pH677Y}$ ) and activation segment (pR721F) in NTRK3, encoding a neurotrophic growth factor receptor tyrosine kinase, were detected in breast and NSCLC. Mutations in NTRK3 were also detected in a screen of the tyrosine kinases in colorectal cancers (Bardelli et al. 2003). The clustering of somatic mutations in key highly conserved residues and between tumor types suggests that NTRK3 mutations are likely contributory to oncogenesis. Likewise, kinase domain mutations in both the primary and follow-up screen of NSCLC were detected in AURKC (STK13) encoding the aurora kinase $\mathrm{C}$ chromosomal pas- 
senger protein implicated in centrosome/spindle regulation during mitosis. The aurora kinases are the target for several inhibitors in clinical development (Andrews 2005). The extent of $A U R K C$ involvement in breast and lung cancers needs to be further investigated to potentially leverage these new therapeutics for these cancers.

\section{CONCLUSIONS}

Our resequencing efforts to date have provided evidence for multiple, infrequently mutated kinases in human cancer. Indeed, commonly mutated protein kinases such as $B R A F$, previously identified in a pilot screen in our laboratory (Davies et al. 2002), may well be the exception rather than the rule. Mutation screening of the protein kinases published for colorectal cancer are in agreement with the data presented here (Bardelli et al. 2003; Parsons et al. 2005). Taken together, the data paint a picture of increasing complexity of human cancer with any number of infrequently mutated protein kinases playing a role in oncogenesis. If such is the case, much larger studies will be needed to garner the statistical genetic support for discriminating between rare oncogenic and passenger mutations. New approaches for functional characterization involving high-throughput cell biological assays will be needed to further investigate the effects of these mutations. Newly developed animal model systems for introduction of multiple mutant alleles into specific tissues of the mouse, such as the Sleeping Beauty transposon system (Collier et al. 2005), will need to be exploited. The development of targeted therapeutics becomes more challenging if multiple small-molecule inhibitors are required to make a major impact on a given cancer type.

The data presented here represent the most in-depth look at the state of cancer genomes at the sequence level published to date. It is hoped that this work will help to inform future large-scale efforts such that we can begin to affect treatment of this complex set of diseases at pace and begin to deliver on the promise of the human genome sequence.

\section{ACKNOWLEDGMENTS}

We are indebted to all of the patients who participated in the studies described here, our collaborators, and all members of the Cancer Genome Project, past and present. This work was supported by the Wellcome Trust.

\section{REFERENCES}

Andrews P.D. 2005. Aurora kinases: Shining lights on the therapeutic horizon? Oncogene 24: 5005.

Bardelli A., Parsons D.W., Silliman N., Ptak J., Szabo S., Saha S., Markowitz S., Willson J.K.V., Parmigiani G., Kinzler K.W., Vogelstein B., and Velculescu V.E. 2003. Mutational analysis of the tyrosine kinome in colorectal cancers. Science 300: 949.

Bignell G., Smith R., Hunter C., Stephens P., Davies H., Greenman C., Teague J., Butler A., Edkins S., Stevens C., O'Meara S., Parker A., Avis T., Barthorpe S., Brackenbury L., Buck G., Clements J., Cole J., Dicks E., Edwards K., Forbes S., Gorton M., Gray K., Halliday K., Harrison R., Hills K., Hinton J., Jones D., Kosmidou V., Laman R., Lugg R., Menzies A., Perry
J., Petty R., Raine K., Shepherd R., Small A., Solomon H., Stephens Y., Tofts C., Varian J., Webb A., West S., Widaa S., Yates A., Gillis A.J.M., Stoop H.J., Gurp R.J.H.L.M.v., Oosterhuis J.W., Looijenga L.H., Futreal P.A., Wooster R., and Stratton M.R. 2005. Sequence analysis of the protein kinase gene family in human testicular germ-cell tumours of adolescents and adults. Genes Chromosomes Cancer. 45: 42.

Cappellen D., De Oliveira C., Ricol D., de Medina S., Bourdin J., Sastre-Garau X., Chopin D., Thiery J., and Radvanyi F. 1999. Frequent activating mutations of FGFR3 in human bladder and cervix carcinomas. Nat. Genet. 23: 18.

Collier L.S., Carlson C.M., Ravimohan S., Dupuy A.J., and Largaespada D.A. 2005. Cancer gene discovery in solid tumours using transposon-based somatic mutagenesis in the mouse. Nature 436: 272.

Davies H., Bignell G.R., Cox C., Stephens P., Edkins S., Clegg S., Teague J., Woffendin H., Garnett M.J., Bottomley W., Davis N., Dicks E., Ewing R., Floyd Y., Gray K., Hall S., Hawes R., Hughes J., Kosmidou V., Menzies A., Mould C., Parker A., Stevens C., Watt S., Hooper S., Wilson R., Jayatilake H., Gusterson B.A., Cooper C., Shipley J., Hargrave D., Pritchard-Jones K., Maitland N., Chenevix-Trench G., Riggins G.J., Bigner D.D., Palmieri G., Cossu A., Flanagan A., Nicholson A., Ho J.W., Leung S.Y., Yuen S.T., Weber B.L., Seigler H.F., Darrow T.L., Paterson H., Marais R., Marshall C.J., Wooster R., Stratton M.R., and Futreal P.A. 2002. Mutations of the BRAF gene in human cancer. Nature 417: 949.

Davies H., Hunter C., Smith R., Stephens P., Greenman C., Bignell G., Teague J., Butler A., Edkins S., Stevens C., Parker A., O’Meara S., Avis T., Barthorpe S., Brackenbury L., Buck G., Clements J., Cole J., Dicks E., Edwards K., Forbes S., Gorton M., Gray K., Halliday K., Harrison R., Hills K., Hinton J., Jones D., Kosmidou V., Laman R., Lugg R., Menzies A., Perry J., Petty R., Raine K., Shepherd R., Small A., Solomon H., Stephens Y., Tofts C., Varian J., Webb A., West S., Widaa S., Yates A., Brasseur F., Cooper C.S., Flanagan A.M., Green A., Knowles M., Leung S.Y., Looijenga L.H.J., Malkowicz B., Pierotti M.A., Teh B.T., Yuen S.T., Lakhani S.R., Easton D.F., Weber B.L., Goldstraw P., Nicholson A.G., Wooster R., Stratton M.R., and Futreal P.A. 2005. Somatic mutations of the protein kinase gene family in human lung cancer. Cancer Res. 65: 7591.

Futreal P.A., Coin L., Marshall M., Down T., Hubbard T., Wooster R., Rahman N., and Stratton M.R. 2004. A census of human cancer genes. Nat. Rev. Cancer 4: 177.

Gorre M.E., Mohammed M., Ellwood K., Hsu N., Paquette R., Rao P.N., and Sawyers C.L. 2001. Clinical resistance to STI571 cancer therapy caused by BCR-ABL gene mutation or amplification. Science 293: 876.

Kobayashi S., Boggon T.J., Dayaram T., Janne P.A., Kocher O., Meyerson M., Johnson B.E., Eck M.J., Tenen D.G., and Halmos B. 2005. EGFR mutation and resistance of non-small-cell lung cancer to gefitinib. N. Engl. J. Med. 352: 786.

Lynch T.J., Bell D.W., Sordella R., Gurubhagavatula S., Okimoto R.A., Brannigan B.W., Harris P.L., Haserlat S.M., Supko J.G., Haluska F.G., Louis D.N., Christiani D.C., Settleman J., and Haber D.A. 2004. Activating mutations in the epidermal growth factor receptor underlying responsiveness of nonsmall-cell lung cancer to gefitinib. N. Engl. J. Med. 350: 2129.

Manning G., Whyte D.B., Martinez R., Hunter T., and Sudarsanam S. 2002. The protein kinase complement of the human genome. Science 298: 1912.

Oosterhuis J.W. and Looijenga L.H.J. 2005. Testicular germ-cell tumours in a broader perspective. Nat. Rev. Cancer 5: 210.

Paez J.G., Janne P.A., Lee J.C., Tracy S., Greulich H., Gabriel S., Herman P., Kaye F.J., Lindeman N., Boggon T.J., Naoki K., Sasaki H., Fujii Y., Eck M.J., Sellers W.R., Johnson B.E., and Meyerson M. 2004. EGFR mutations in lung cancer: Correlation with clinical response to gefitinib therapy. Science 304: 1497.

Pao W., Miller V., Zakowski M., Doherty J., Politi K., Sarkaria I., Singh B., Heelan R., Rusch V., Fulton L., Mardis E., Kupfer D., Wilson R., Kris M., and Varmus H. 2004. EGF receptor gene mutations are common in lung cancers from "never smokers" 
and are associated with sensitivity of tumors to gefitinib and erlotinib. Proc. Natl. Acad. Sci. 101: 13306.

Parsons D.W., Wang T.-L., Samuels Y., Bardelli A., Cummins J.M., DeLong L., Silliman N., Ptak J., Szabo S., Willson J.K.V., Markowitz S., Kinzler K.W., Vogelstein B., Lengauer C., and Velculescu V.E. 2005. Colorectal cancer mutations in a signalling pathway. Nature 436: 792.

Sasaki H., Shimizu S., Endo K., Takada M., Kawahara M., Tanaka H., Matsumura A., Iuchi K., Haneda H., Suzuki E., Kobayashi Y., Yano M., and Fujii Y. 2005. EGFR and erbB2 mutation status in Japanese lung cancer patients. Int. J. Cancer 118: 180 .

Sawyers C. 2004. Targeted cancer therapy. Nature 432: 294.

Shigematsu H., Takahashi T., Nomura M., Majmudar K., Suzuki M., Lee H., Wistuba I.I., Fong K.M., Toyooka S., Shimizu N., Fujisawa T., Minna J.D., and Gazdar A.F. 2005. Somatic mutations of the HER2 kinase domain in lung adenocarcinomas. Cancer Res. 65: 1642.

Slamon D.J., Leyland-Jones B., Shak S., Fuchs H., Paton V., Bajamonde A., Fleming T., Eiermann W., Wolter J., Pegram M., Baselga J., and Norton L. 2001. Use of chemotherapy plus a monoclonal antibody against HER2 for metastatic breast cancer that overexpresses HER2. N. Engl. J. Med. 344: 783.

Stephens P., Hunter C., Bignell G., Edkins S., Davies H., Teague J., Stevens C., O'Meara S., Smith R., Parker A., Barthorpe A., Blow M., Brackenbury L., Butler A., Clarke O., Cole J., Dicks E., Dike A., Drozd A., Edwards K., Forbes S., Foster R., Gray K., Greenman C., Halliday K., Hills K., Kosmidou V., Lugg R., Menzies A., Perry J., Petty R., Raine K., Ratford L., Shepherd
R., Small A., Stephens Y., Tofts C., Varian J., West S., Widaa S., Yates A., Brasseur F., Cooper C.S., Flanagan A.M., Knowles M., Leung S.Y., Louis D.N., Looijenga L.H.J., Malkowicz B., Pierotti M.A., Teh B., Chenevix-Trench G., Weber B.L., Yuen S.T., Harris G., Goldstraw P., Nicholson A.G., Futreal P.A., Wooster R., and Stratton M.R. 2004. Lung cancer: Intragenic ERBB2 kinase mutations in tumours. Nature 431: 525 .

Stephens P., Edkins S., Davies H., Greenman C., Cox C., Hunter C., Bignell G., Teague J., Smith R., Stevens C., O’Meara S., Parker A., Tarpey P., Avis T., Barthorpe A., Brackenbury L., Buck G., Butler A., Clements J., Cole J., Dicks E., Edwards K., Forbes S., Gorton M., Gray K., Halliday K., Harrison R., Hills K., Hinton J., Jones D., Kosmidou V., Laman R., Lugg R., Menzies A., Perry J., Petty R., Raine K., Shepherd R., Small A., Solomon H., Stephens Y., Tofts C., Varian J., Webb A., West S., Widaa S., Yates A., Brasseur F., Cooper C.S., Flanagan A.M., Green A., Knowles M., Leung S.Y., Looijenga L.H.J., Malkowicz B., Pierotti M.A., Teh B., Yuen S.T., Nicholson A.G., Lakhani S., Easton D.F., Weber B.L., Stratton M.R., Futreal P.A., and Wooster R. 2005. A screen of the complete protein kinase gene family identifies diverse patterns of somatic mutations in human breast cancer. Nat. Genet. 37: 590.

Weinstein I.B. 2002. Cancer. Addiction to oncogenes-The Achilles heal of cancer. Science 297: 63.

Wilkie A., Patey S., Kan S., van den Ouweland A., and Hamel B. 2002. FGFs, their receptors, and human limb malformations: Clinical and molecular correlations. Am. J. Med. Genet. 112: 266. 


\title{
$8_{8}^{\infty} \mathrm{CSH} \&$ Cold Spring Harbor Symposia SYMPOSIA on Quantitative Biology
}

\section{Somatic Mutations in Human Cancer: Insights from Resequencing the Protein Kinase Gene Family}

\author{
P.A. FUTREAL, R. WOOSTER and M.R. STRATTON
}

Cold Spring Harb Symp Quant Biol 2005 70: 43-49

Access the most recent version at doi:10.1101/sqb.2005.70.015

References This article cites 24 articles, 8 of which can be accessed free at: http://symposium.cshlp.org/content/70/43.full.html\#ref-list-1

License

Email Alerting Receive free email alerts when new articles cite this article - sign up in Service the box at the top right corner of the article or click here. 